Review

\title{
Some Remarks towards a Better Understanding of the Use of Concrete Recycled Aggregate: A Review
}

\author{
Anna M. Grabiec ${ }^{1}$, Jeonghyun Kim ${ }^{2} * * \mathbb{C}$, Andrzej Ubysz ${ }^{2}\left(\mathbb{D}\right.$ and Pilar Bilbao ${ }^{3} \mathbb{C}$ \\ 1 Faculty of Environmental Engineering and Mechanical Engineering, Poznań University of Life Sciences, \\ Piątkowska 94, 60-649 Poznań, Poland; agra@up.poznan.pl \\ 2 Faculty of Civil Engineering, Wrocław University of Science and Technology, Wybrzeże Wyspiańskiego 27, \\ 50-370 Wrocław, Poland; andrzej.ubysz@pwr.edu.pl \\ 3 Faculty of Architecture and Urbanism, National University of La Plata, 7 Avenue 776, \\ La Plata B1900, Argentina; pilibilbao@gmail.com \\ * Correspondence: jeonghyun.kim@pwr.edu.pl
}

Citation: Grabiec, A.M.; Kim, J.; Ubysz, A.; Bilbao, P. Some Remarks towards a Better Understanding of the Use of Concrete Recycled Aggregate: A Review. Sustainability 2021, 13, 13336. https://doi.org/ $10.3390 /$ su132313336

Academic Editor: Jorge de Brito

Received: 18 October 2021

Accepted: 29 November 2021

Published: 2 December 2021

Publisher's Note: MDPI stays neutral with regard to jurisdictional claims in published maps and institutional affiliations.

Copyright: (c) 2021 by the authors. Licensee MDPI, Basel, Switzerland. This article is an open access article distributed under the terms and conditions of the Creative Commons Attribution (CC BY) license (https:// creativecommons.org/licenses/by/ $4.0 /)$.
Abstract: Research on recycled concrete aggregates (RCAs) has been progressively advanced. Beyond replacing natural aggregates with RCA, discussions have been held on the effect of the parent concrete and repeatedly recycled aggregate concrete. Although it has been reported that RCA can be technically used for structural concrete, due to several other factors, RCA is mainly used for sub-bases. Therefore, identifying these factors is the key to promoting the use of RCA. Therefore, this review study first briefly summarizes the physical and chemical characteristics of RCA compared to natural aggregate, and reviews the effects of parent concrete and repeatedly recycled aggregate on next generation concrete. This study also briefly discusses the RCA standards of various countries and the factors that hinder the widespread use of RCA. The results show that there is a correlation in properties between parent concrete and the next generation concrete, and the properties of concrete decrease when RCA is used repeatedly. In addition, on the basis of the literature review, factors hindering the use of RCA were found to be unstable supply and demand, economic feasibility, and negative perceptions.

Keywords: recycled concrete aggregate; recycled aggregate concrete; residual mortar; reusing; sustainability

\section{Introduction}

According to the annual Mineral Commodity Summaries issued by the US Geological Survey [1], $88 \%$ of about 1.5 billion tons of crushed aggregate consumed in the United States in 2020 was used in construction and cement manufacturing. Moreover, 960 million tons of construction sand and gravel were produced in the United States in 2020, of which $46 \%$ was used for concrete.

In Europe, it is also reported that $25 \%$ and $15 \%$ of aggregates are used in ready-mixed concrete and precast concrete, respectively [2]. The global construction aggregate and cement market, including developing countries such as China and India, is expected to grow steadily by 2030 [3]. However, the dark side of this growth in construction is related to environmental issues. The cement industry is responsible for about $7 \%$ of global anthropogenic carbon dioxide $\left(\mathrm{CO}_{2}\right)$ emission, and $36.4 \%$ of the total waste generated in the EU-28 in 2016 came from the construction sector [4]. The annual construction and demolition (C\&D) waste in the United States has increased by about 3.5 times from 170 million tons in 2005 to 600 million tons in 2018 [5]. Shi and Xu [6] have predicted that the mass of $C \& D$ waste in China will soon reach 650 million tons. According to the literature of Sobotka et al. [7] published in 2016, C\&D waste generated in Poland in 2022 was predicted to be 5.5 million tons, but in 2018 it already exceeded 6.7 million tons [8]. That 
confirms the $C \& D$ waste is expected to increase due to deteriorated infrastructures $[9,10]$. Therefore, the effective recycling of $C \& D$ waste is an immediate challenge.

The time when the use of recycled concrete aggregate (RCA) to make concrete began was in the 40s of the 20th century, when on the one hand, there was a need to cope with the huge amount of building debris resulting from the destruction of the war, and on the other hand, to find a low-cost and easily accessible material for the construction of new buildings. According to Levy and Helene 2002, via Aragão [11], it is for this reason that 1946 can be considered as the starting date of the period in which the new concept of recycled aggregate concrete (RAC) was developed. The focus was on the construction of new buildings using concrete and ceramic debris, mainly for foundations. The ecological aspects, if one can speak of them at all, were certainly of very little importance. While after 1945 , the increase in interest in RCA was due to the social and economic crisis (shortage of financial resources and building materials), today's increase in interest is the outcome of the environmental and social crisis. The subsequent reports of the Intergovernmental Panel of Climate Changes (IPPC) and the UN report Ecosystems and Human Well-being: Assessment [12] are significant in this regard. Quite free, and in many cases uncontrolled, use of natural resources for the purposes of civilization, runs the risk of disrupting many natural systems [13]. The current crisis is therefore forcing an intensification of efforts to protect the environment in all areas of human industrial activity, including the building industry.

Concrete waste, one of the major compositions of C\&D waste, is produced as RCA through the crushing, separating, and screening process, and it is used as a substitute for natural aggregate (NA). However, since the RCA consists of original aggregate and residual mortar, RCA and NA can be considered as similar materials, but the properties of the two materials are different. Therefore, the properties of concrete using RCA are different from those of using NA. In general, concrete made with RCA not only decreases the density and workability in the fresh state but also decreases the mechanical properties and durabilityrelated performance of hardened state concrete compared to natural aggregate concrete (NAC) [13-16].

The undisputed leader in concrete recycling is Japan, where the recycling of materials from demolition and deconstructing already accounted for 92\% in 2005 [17]. Moreover, about $88 \%$ of the construction waste generated in the EU is reused [18], but due to the poor properties of RAC mentioned above, the RCA is mainly used in the most primary way, such as road base and road leveling [19]. Therefore, the value-added of RCA was one of the challenging tasks, and a variety of studies were conducted to improve the properties of RAC for using it in various areas. As research data were accumulated, it was reported that RCA could be used for the production of structural concrete [20,21]. However, apart from the performance of RAC, there are other major factors that hinder the use of RCA and RAC which have not been discussed sufficiently.

Basically, the untreated RAC does not act as well as NAC in terms of mechanical properties and durability performance [22-26]. However, the applicability of the RCA to concrete is clear $[27,28]$, and RCA is practically being used for concrete production [10,29]. In this context, research on RCA and RAC is progressing. Beyond the study on the possibility of replacing NA with RCA, the effect of parent concrete on the properties of nextgeneration concrete and the effect of repeated use of RCA on the properties of RCA and RAC were investigated. The former case is important in terms of better utilization of RCA and prediction of the property development of RAC, but the latter is particularly crucial in the long term as it relates to the reuse of RCA. Although extensive review papers on RCA and RAC have been published by some researchers (e.g., [30-35]), many of these deal with the correlation between RCA replacement and the performance of RAC, there has been little discussion on the effect of the properties of the parent concrete on the properties of the next-generation RAC, and in particular the properties of RAC that is repeatedly recycled. This gap may be because there are not enough data to discuss, as studies on the reuse of RCA [36-42] have been conducted by a few researchers in recent years. Nevertheless, identifying the factors hindering the widespread use of RCA and evaluating the effects of 
multiple recycling of RCA on the properties of concrete need to be addressed as they are key points for achieving sustainability in the construction industry.

This paper is structured as follows. Section 1 describes the significance of this research. Section 2 briefly addresses the properties and production of RCA. Section 3 deals with the effect of parent concrete and multiple uses of RCA on the properties of the nextgeneration RCA and RAC. This section includes a discussion of RCA standards for concrete in selected countries and several factors that hinder the use of RCA. The last section presents the conclusions.

\section{Recycled Concrete Aggregate}

\subsection{Characteristics}

RCA produced from C\&D waste is made up of old residual mortar and NA (i.e., original aggregate) (Figure 1). This residual mortar sticks to the original aggregate and is considered a major factor that distinguishes RCA from NA [43]. The presence of the residual mortar lowers densities of the RCA and raises its water absorption capacity, and it contributes to the reduction in the mechanical strength and durability performance of RAC [44-47].

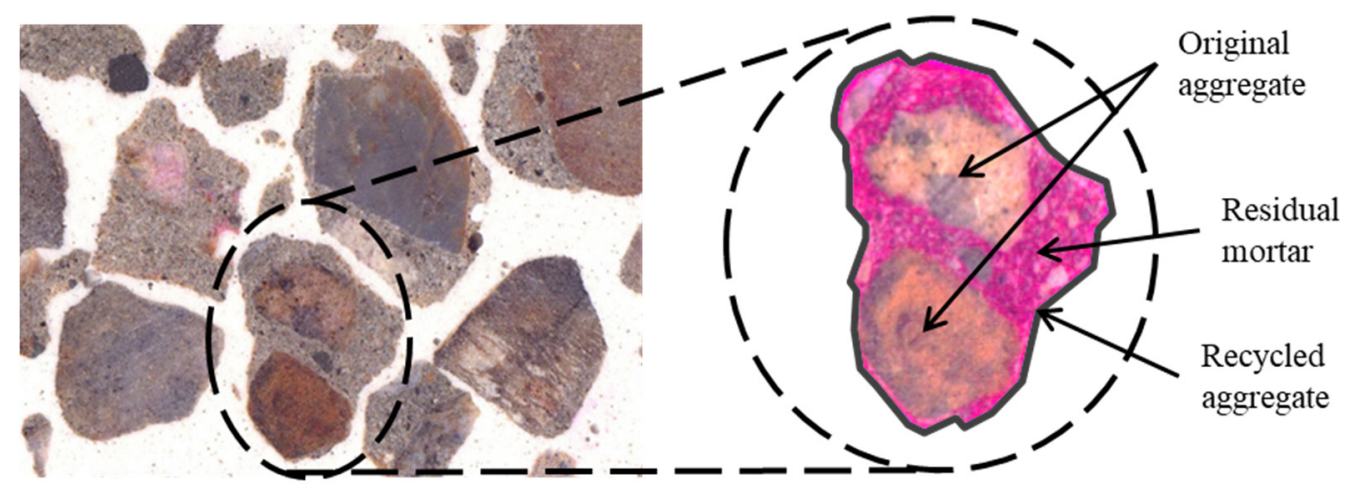

(a) Recycled aggregate concrete with white cement

(b) Recycled aggregate with $1 \%$ phenolphthalein solution

Figure 1. A sectional view of RAC (a) and RCA (b).

Figure 2 presents the relationship between residual mortar content, water absorption and specific gravity of NA and RCA studied by various research groups. The specific gravity of NA is mostly distributed in the range of 2.6 to 2.8 and the water absorption ratio is less than $2 \%$, whereas, for the RCA, the water absorption ranges between $2 \%$ and $8 \%$, and the specific gravity is distributed between about 2.3 and 2.5. A direct comparison of water absorption and density by residual mortar content may not be meaningful, as the original aggregate of the RCA used in each literature is not the same, but it seems clear that the content of residual mortar is inversely proportional to the density of RCA and directly proportional to the water absorption capacity.

The content of residual mortar may also be closely related to the size of RCA. Juan and Gutiérrez [48] investigated the effect of the size of RCA on the residual mortar content and noted that the residual mortar content of 4-8 mm fraction of RCA ranges from $33 \%$ to $55 \%$, while it has $23 \%$ to $44 \%$ for $8-16 \mathrm{~mm}$ fraction. Similarly, in the study by Suryawanshi et al. [49], it was observed that the residual mortar content in the $4.75-10 \mathrm{~mm}$ fraction was $27 \%$ higher than that in the $10-20 \mathrm{~mm}$ fraction. On the contrary, of the total three groups of RCA used in the study [44], two had around 3\% higher residual mortar content in the 5-10 mm fraction, while the other RCA had about 10\% lower residual mortar content in the 5-10 mm fraction. Abbas et al. [50] sorted two different RCAs into four groups by size, respectively, and tested the residual mortar content. One of the two RCAs had the highest residual mortar content in the order of $19 \mathrm{~mm}, 4.75 \mathrm{~mm}, 12.7 \mathrm{~mm}$, and 
$9.5 \mathrm{~mm}$, while for another RCA, the residual mortar content gradually increased from the smallest to the largest aggregates.

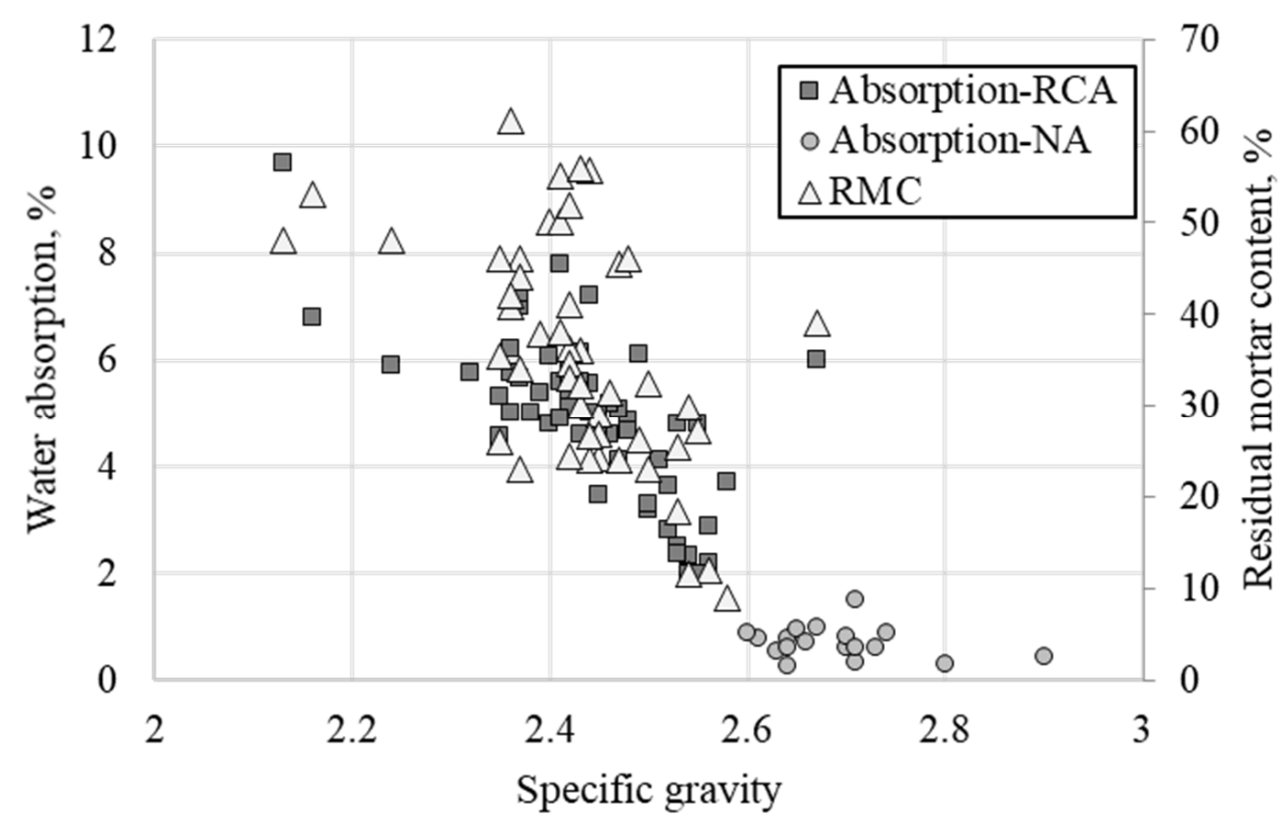

Figure 2. Physical properties of NA and RCA [44,48,51-72].

In addition to physical characteristics, RCA differs in chemical composition from NA. Figure 3 shows the relationship of chemical composition between calcium oxide $(\mathrm{CaO})$ and silicon dioxide $\left(\mathrm{SiO}_{2}\right)$ in ordinary Portland cement, NA and RCA. Since the cement is produced to meet the composition required by standards [73,74], $\mathrm{CaO}$ and $\mathrm{SiO}_{2}$ were concentrated at about $62 \%$ and $22 \%$, respectively [71,75-77]. For NA used in various studies, the amount of $\mathrm{SiO}_{2}$ was in the range of about $50-63 \%$, and $\mathrm{CaO}$ was mainly less than $10 \%[58,75,76,78-80]$. For RCA, which is a mixture of original aggregate and residual mortar, the $\mathrm{SiO}_{2}$ content was lower and the $\mathrm{CaO}$ was higher than those of NA, distributed between ordinary Portland cement and NA [58,75,76,78-83].

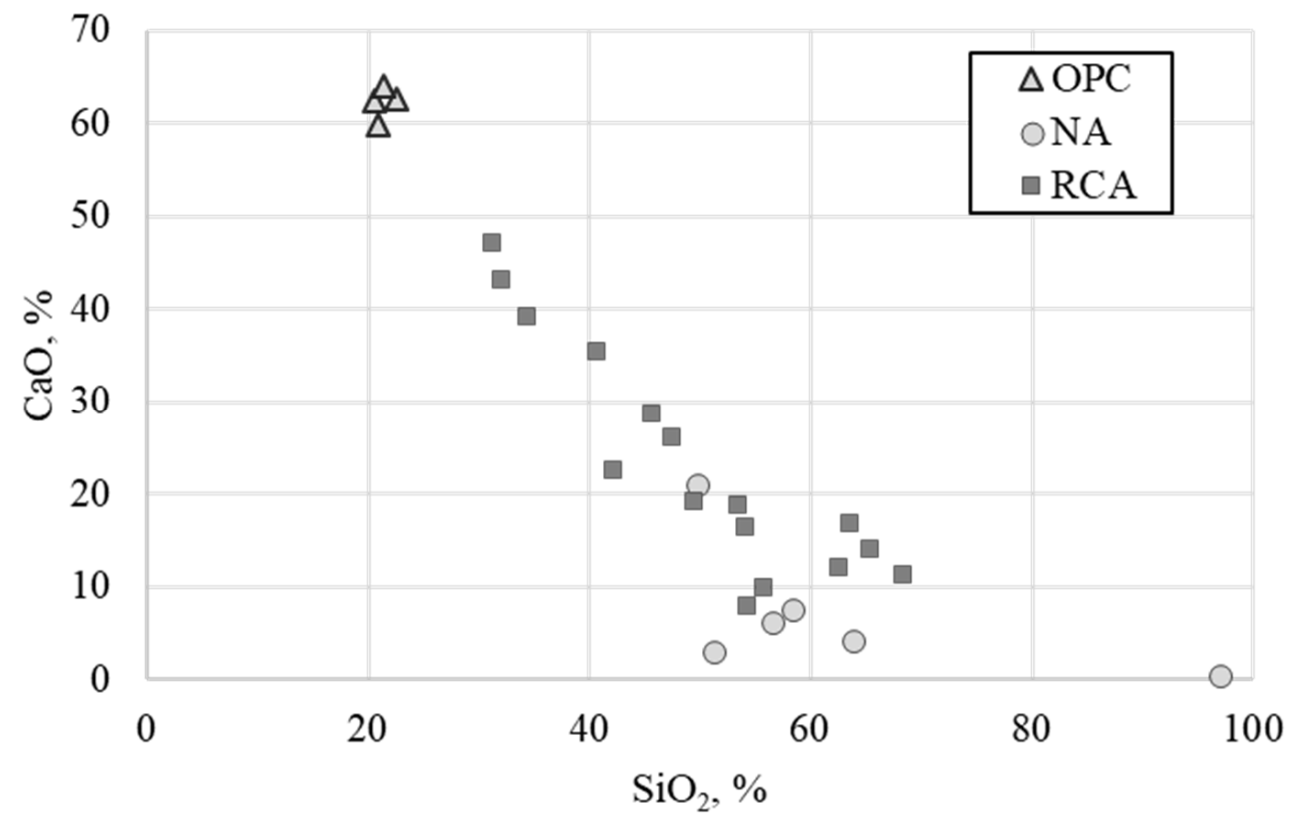

Figure 3. Chemical composition of ordinary Portland cement (OPC), NAs and RCAs [58,71,75-83]. 
Although it may not be appropriate to compare the properties of RCAs used in different studies due to geological differences, there appears to be a correlation between the chemical composition and physical properties of RCA. According to a study by Kim et al. [58], when RCAs are obtained from the same source of parent concrete, the CaO content decreases and the $\mathrm{SiO}_{2}$ content increases with a lower residual mortar content.

\subsection{Production of Recycled Concrete Aggregate}

In order to produce RCA with the suitable size as a construction material $(0-40 \mathrm{~mm})$ from massive C\&D waste, concrete debris must go through a series of essential processes in which mechanical crushing is mainly employed. This basically consists of crushing to obtain size fractions suitable for use; magnetic separation to remove ferrous metals; a separation by air blowers to get rid of the nonmagnetic substance, such as paper, wood, plastic and dust; and screenings to sort the produced RCA by size (Figure 4). The quality of the RCA produced is affected by the type and specification of the recycling facility $[84,85]$.

Regarding the effect of the type of crushers, Matias et al. [86] reported that RCA subjected to primary crushing by a jaw crusher had a lower shape index than RCA subjected to secondary crushing using an impact crusher. In other words, the aggregate that has only undergone the primary crushing has a more angular shape, and the one that has gone through the secondary crushing was more rounded. Öztürk et al. [87] fabricated RAC mixtures with RCA produced by impact crusher and vertical shaft crusher, respectively, and reported that RAC with RCA from the impact crusher showed a higher compressive strength than that of RAC from the vertical shaft crusher. On the contrary, Cepuritis et al. [88] noted that sand produced by the vertical shaft crusher showed a consistent shape and is more favorable for concrete than sand produced by milling or a cone crusher. Moreover, Ulsen et al. [89] reported that the residual mortar content, density, and particle size distribution of RCA produced by the jaw crusher and impact crusher were similar. However, the influence of the crusher type on the aggregate may vary due to factors such as rock types [90,91].

A meaningful trend is observed between the number of crushing and the physical characteristics of RCA. Nagataki et al. [92] crushed RCA three times by a combination of the impact crusher and the mechanical grinder (i.e., impact crusher-mechanical grindermechanical grinder), and compared its density, water absorption capacity, and residual mortar content. Compared to the primary crushed RCA, the tertiary crushed RCA increased in density by about $4.5 \%$, and water absorption and residual mortar content decreased by $1.7-2.5 \%$ and $20 \%$, respectively. Moreover, cracks in the RCA were observed after mechanical grinding, but the authors noted that it was negligible. Similarly, Pedro et al. [93] first crushed RCA with a jaw crusher and secondarily crushed the RCA with a hammer mill, and compared the density and water absorption for each RCA. As a result, a significant change was not observed in the density, but the water absorption of all six aggregates used in the test decreased by $0.2-1.5 \%$. Regarding the number of crushing, the Korea Resource Recycling Association divided the production of RCA into four stages based on the purpose of use: primary crushing for the use of filling and leveling; secondary crushing for sub-base of the road pavement; tertiary crushing for the production of high-quality RCA; quaternary crushing for the production of sand for concrete [94]. 


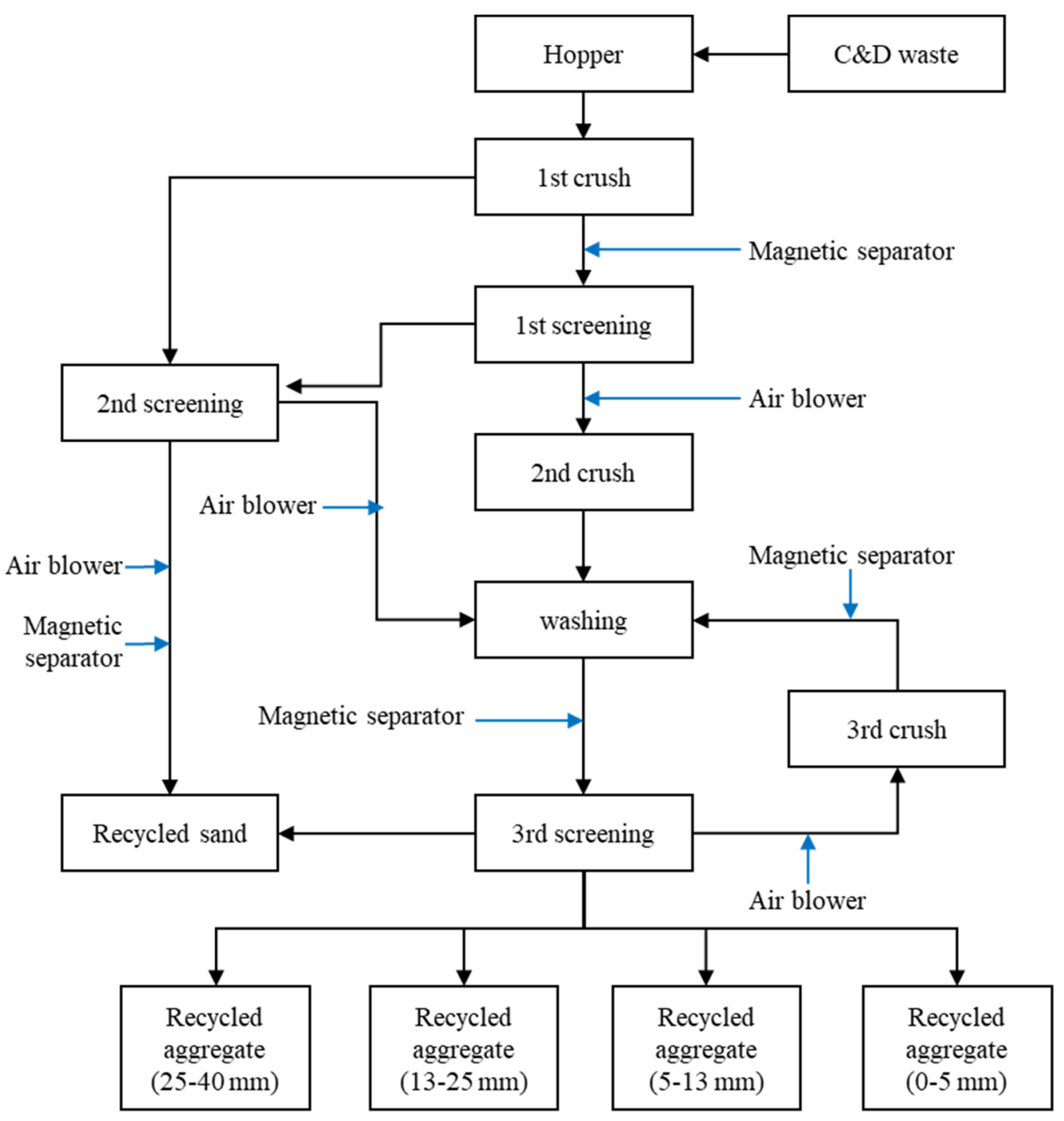

Figure 4. Scheme of RCA production (adapted from [94]).

RCA can be produced in mobile or stationary recycling plants. Regarding the recycling of C\&D waste, the place where RCA is produced is one of the crucial factors. In general, mobile plants that produce RCA at construction and demolition sites do not need to transport $C \& D$ waste to stationary recycling plants, but the ability to remove impurities and residual mortar is relatively low. On the other hand, stationary recycling plants can produce high-quality RCA through several stages of crushing and screening, but transportation of C\&D waste from the construction site to the recycling plant is involved [33]. Tam and Tam [95] stated that collecting concrete waste from different sources and managing it in one plant can cause an average effect, which can hinder the use of high-quality RCA and low-quality RCA for each purpose. On the contrary, Hiete [96] argued that the down-cycle of using RCA as a sub-base for road construction and reclamation remains dominant. Thus, for up-cycling, RCA needs to be processed in stationary plants capable of producing high-quality RCA.

The ultimate purpose of the concrete waste recycling process is to produce highquality RCA that can minimize performance degradation of concrete when replacing NA with RCA by removing the residual mortar as much as possible. Thus, the following methods have been proposed to remove residual mortar: the hydrochloric acid dissolution method [97,98], the freeze-and-thaw method [50], the thermal shock method [48], the microwave method [99], and the high-performance sonic impulse method [100]. Moreover, technologies utilizing $\mathrm{CO}_{2}$ [101] and bacteria [102] have been reported to show the 
potential to improve the performance of RCA and RAC. However, in a study on the energy consumption of RCA processing techniques conducted by Quattrone et al. [103], the fuel-fed thermo-mechanical processes are found to consume about 36-62 times more energy in producing RCA than traditional recycling processes consisting of crushing-separating-screening.

\section{Recycled Aggregate Concrete}

\subsection{The Effect of Parent Concrete on the Properties of Next Generation Concrete}

Research on RAC has further progressed from the effect of the RCA replacement ratio to the effect of the parent concrete on the next generation concrete, and this replacement, as well as the compressive strength of parent concrete are crucial in influencing the quality of next generation concrete.

Ahmad Bhat [104] produced low-, medium- and high-strength RCAs by crushing parent concretes with different compressive strengths of $20 \mathrm{MPa}, 40 \mathrm{MPa}$, and $60 \mathrm{MPa}$, respectively. Using the three RCAs produced, a total of 18 series of RACs were manufactured: 6 series of RAC with target strengths of 20,40 and $60 \mathrm{MPa}$ at $50 \%$ and $100 \%$ replacement ratios using RCA obtained from the $20 \mathrm{MPa}$ parent concrete; 6 series of RAC with target strengths of 20,40 and $60 \mathrm{MPa}$ at $50 \%$ and $100 \%$ replacement ratios using RCA obtained from $40 \mathrm{MPa}$ parent concrete; another 6 series of RAC with target strengths of 20,40 and $60 \mathrm{MPa}$ at $50 \%$ and $100 \%$ replacement ratios using RCA obtained from $60 \mathrm{MPa}$ parent concrete (Figure 5). The compressive strength of the low strength concrete with $50 \%$ RCA replacement obtained from high-strength concrete was $9 \%$ higher than that of parent concrete, and the tensile strength was the same as that of parent concrete with NA (Figures 6 and 7). A similar result was noted that RCA obtained from high strength parent concrete can achieve a similar compressive and tensile strength to normal strength concrete with NA [105]. In addition, as frequently observed in other studies [106,107], RAC with $100 \%$ RCA replacement showed lower mechanical strength than RAC with 50\% RCA replacement. Considering the lower physical performance of RCA compared to NA, it is an expected result, and, the relationship between the strength of the parent concrete and the strength of the next generation concrete is also observed.

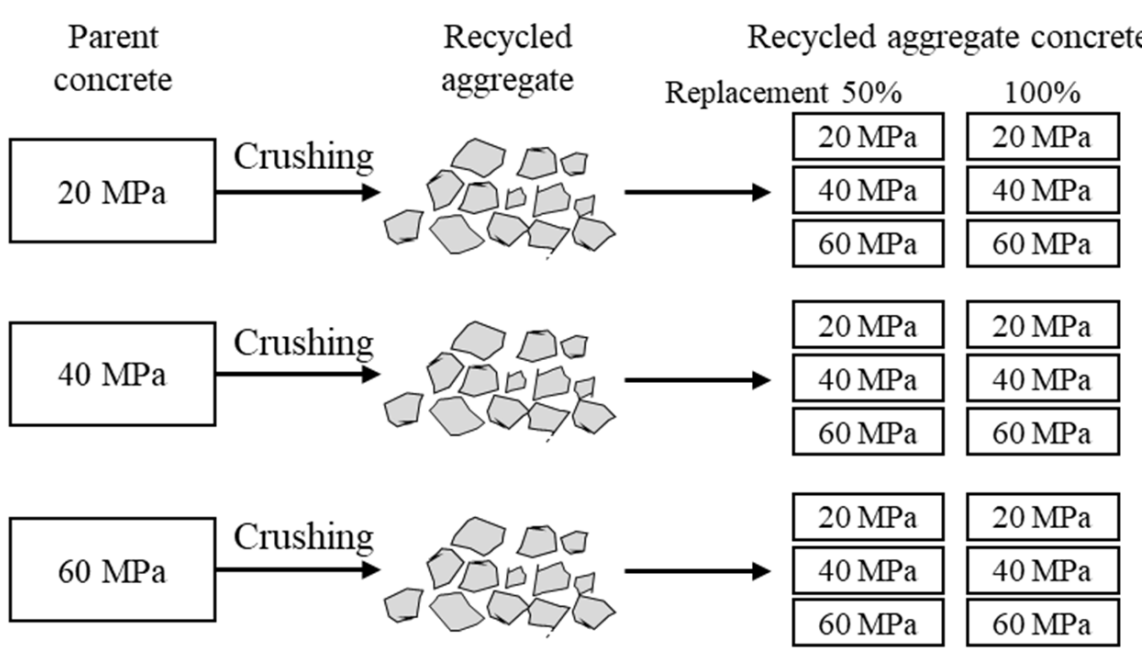

Figure 5. Experimental scheme of the effect of the strength of the parent concrete on the next generation concrete [104]. 


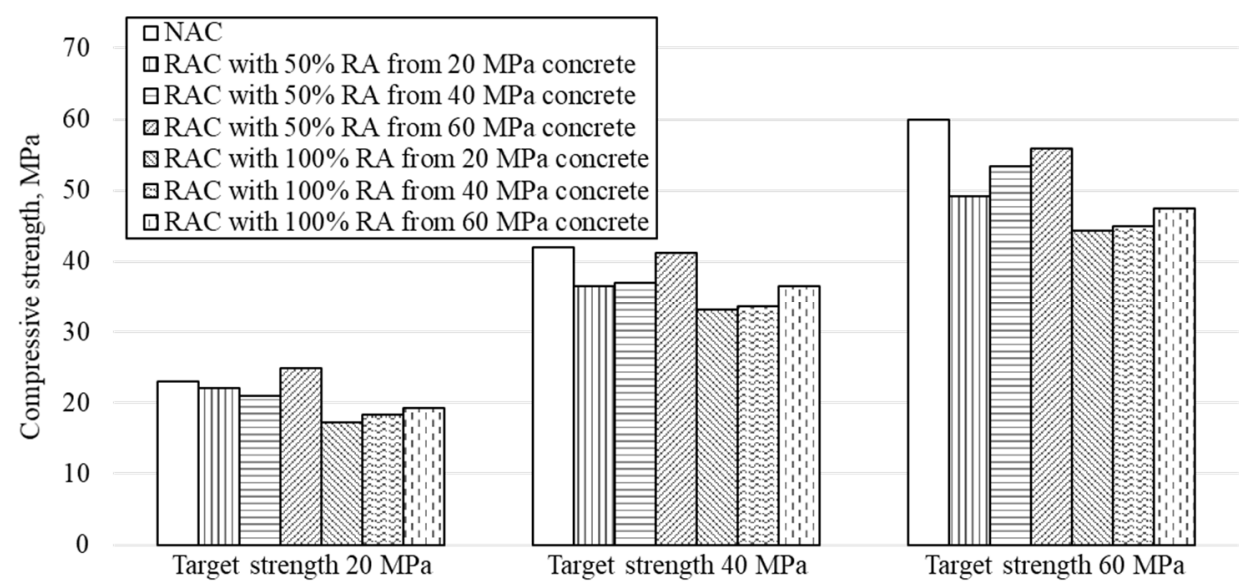

Figure 6. Compressive strength of RAC made from RCA produced from concrete with different strengths [104].

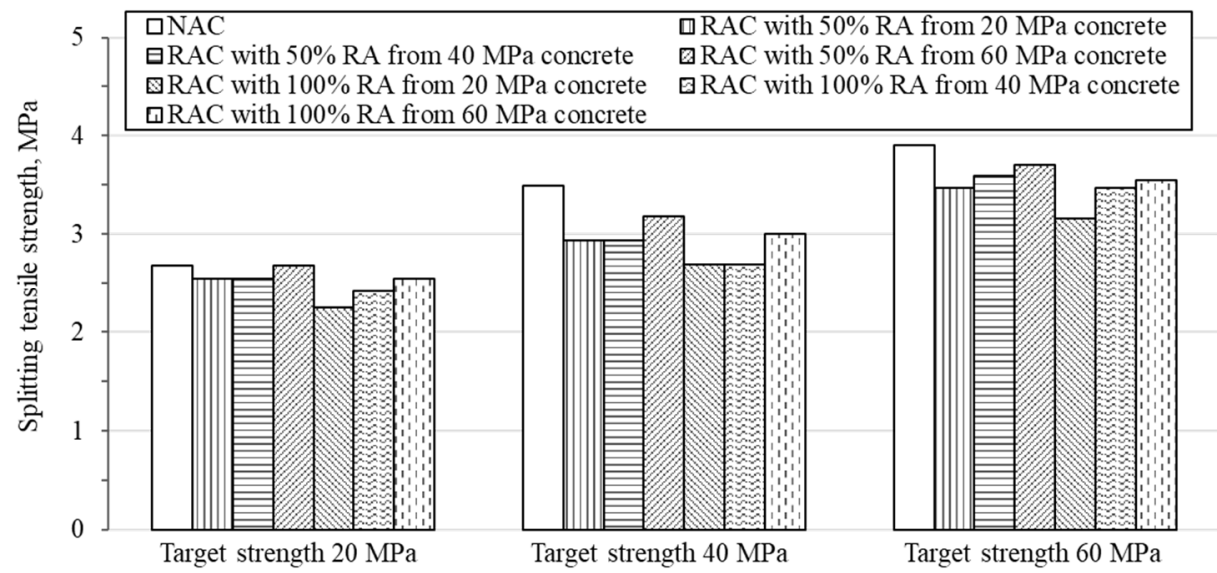

Figure 7. Splitting the tensile strength of RAC made from RCA produced from concrete with different strengths [104].

Kou and Poon [108] assessed the basic characteristics of five RCAs obtained from concrete with different compressive strengths of $30 \mathrm{MPa}, 45 \mathrm{MPa}, 60 \mathrm{MPa}, 80 \mathrm{MPa}$, and $100 \mathrm{MPa}$. As the strength of the parent concrete increased, the water absorption of RCAs decreased, resulting in better quality. Afterwards, a total of 5 series of RACs with a $100 \%$ replacement rate were manufactured using each RCA, and mechanical properties and durability performances were analyzed. As a result of the mechanical properties test of compressive, tensile strength, and elastic modulus, RAC made from RCA obtained from high-strength concrete was found to be superior to RACs with RCA from lowstrength concrete in all tests except for the slump value. Similar trends were observed in drying shrinkage and chloride resistance tests. The authors interpreted that the low water absorption ratio of RCA from high-strength concrete contributes to lower drying shrinkage and chloride penetration.

Gholampour and Ozbakkaloglu [71] made concrete mixtures with target strengths of $40 \mathrm{MPa}$ and $80 \mathrm{MPa}$ using RCAs produced from concretes with a compressive strength of $20 \mathrm{MPa}, 40 \mathrm{MPa}$, and $110 \mathrm{MPa}$, and evaluated the mechanical properties. As shown in Table 1, the performance of concrete made of RCA from high-strength concrete was superior to those of medium- and low-strength concrete with all the selected properties. Unlike the test results in [108], the slump values of RAC made of RCA from high-strength concrete were the same as that of concrete made of RCA produced from medium-strength concrete, and were more workable than that made from low-strength concrete. In particular, for the creep deformation, RAC with low-strength RA was $60 \%$ higher than that of high-strength 
RCA. On the contrary, Padmini et al. [61] reported that low-strength parent concrete, which has a relatively weaker binding force between the residual mortar and the original aggregates than that of high-strength concrete, separates most residual mortar from the RCA surface during the crushing process; thus, a specific gravity of RCA decreases and the water absorption increases as the strength of parent concrete increases. It was observed that the residual mortar content in RCA obtained from the low-strength concrete was less, and for this reason, the RCA of a small size (i.e., $10 \mathrm{~mm}$ ) may have more residual mortar rather than aggregates, which could lead to a greater reduction in mechanical properties. Wang et al. [109] noted that the level of residual mortar content may not be an absolute factor in determining the properties of concrete. In the study, it was reported that the RCA from high-strength parent concrete reduced the shrinkage of RAC at a water-to-cement ratio of 0.30 , even though the RCA had a higher residual mortar content compared to that of RAC with RCA from low-strength parent concrete. However, at the water-tocement ratios of 0.45 and 0.60 , the shrinkage of RAC increased in the order of RCA from low-strength, medium-strength, and high-strength concrete. The authors explained that the lower porosity and uniformly hardened residual mortar of RCA from high-strength concrete could contribute to an increased shrinkage deformation of RAC.

Table 1. Fresh and hardened properties of RAC with RCA from low-, medium-, and high strength parent concrete [71].

\begin{tabular}{|c|c|c|c|c|c|}
\hline \multicolumn{2}{|c|}{ Test } & RAC1 & RAC2 & RAC3 & RAC4 \\
\hline \multicolumn{2}{|c|}{ Compressive strength of parent concrete, $\mathrm{MPa}$} & 40 & 110 & 20 & 110 \\
\hline \multicolumn{2}{|c|}{ Target strength, $\mathrm{MPa}$} & \multicolumn{2}{|c|}{40} & \multicolumn{2}{|c|}{80} \\
\hline \multicolumn{2}{|c|}{ Slump, mm } & 115 & 115 & 140 & 150 \\
\hline \multirow{2}{*}{ Density, $\mathrm{kg} / \mathrm{m}^{3}$} & Fresh & 2351 & 2364 & 2356 & 2407 \\
\hline & Hardened & 2330 & 2345 & 2341 & 2381 \\
\hline \multicolumn{2}{|c|}{ Compressive strength, $\mathrm{MPa}$} & 32.0 & 36.8 & 64.3 & 80.1 \\
\hline \multicolumn{2}{|c|}{ Elastic modulus, GPa } & 26.7 & 29.1 & 31.9 & 41.5 \\
\hline \multicolumn{2}{|c|}{ Tensile strength, $\mathrm{MPa}$} & 3.22 & 3.36 & 3.90 & 5.11 \\
\hline
\end{tabular}

Geng et al. [110] evaluated the effect of the service time of parent concrete (i.e., 1 year, 18 years, and 40 years) on strength development. The compressive strength development of NAC at 1 day was $33 \%$ compared to that at 28 days, while for the RAC with the service life of 1 year, 18 years and 40 years, the strength development decreased to $30 \%$, 24\%, $11 \%$, respectively. However, after longer periods of hardening after 28 days to 90 days, the strength of NAC increased by $17 \%$, whereas RAC gained $21-29 \%$. Therefore, it was emphasized that the existing prediction model for strength development for NAC may not be suitable for RAC.

Something which seems to be of particular importance in the context of RCA use for production of RAC is the possible reactivity of RA as a consequence of NA's reactivity. It is well known that alkali-silica reaction (ASR) is one of the major causes of concrete degradation. In the case of RAC, this problem can be significant depending on the percentage of RCA as a substitute of NA and because of the obvious crushing process [22].

\subsection{The Effect of Repeated Use of Recycled Concrete Aggregate}

Generally, research on RAC has been focused on concrete made from RCA obtained from NAC. However, some researchers studied the reuse of RCA by investigating the effect of repeatedly reused RCA on the properties of RAC. The scheme of repeated use of RCA is shown in Figure 8. 


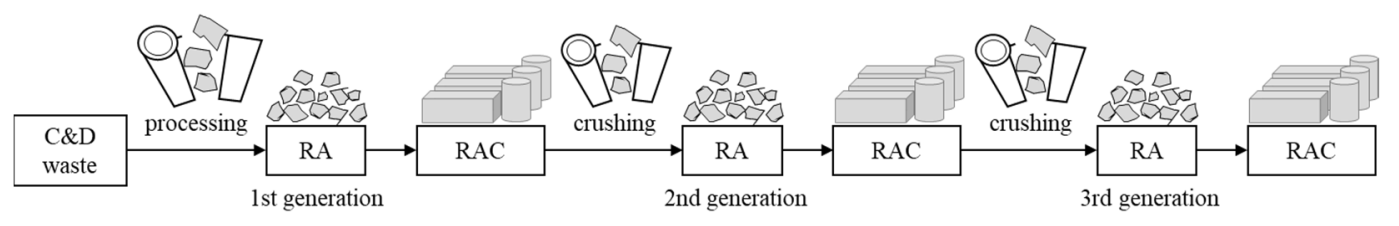

Figure 8. Scheme of the repeated use of RCA and RAC.

Huda and Alam [37] evaluated the effect of RCA reuse on the properties of RCA and RAC by repeating the crushing and casting of RAC a total of three times. For the physical characteristics of RCA, compared to the first generation RCA, the density of the second and third generation RCA decreased by $10 \%$ and $14 \%$, respectively, and the water absorption rate increased by $1.9 \%$ and $4.2 \%$. For the fresh state properties of the RAC, as the number of reuse of RCA increased from the first generation to the third generation, the slump decreased by $6 \%$ and $15 \%$, and air content increased by $0.3 \%$ and $0.5 \%$, respectively. For the mechanical properties, compared with the first generation RAC, the compressive strength and tensile strength of the third generation RAC decreased by $21 \%$ and $36 \%$, respectively, and the elastic modulus decreased by $5 \%$. However, the strengths of the second generation RAC increased by $1 \%$ to $2 \%$. Similar observations were found in several studies. In the study performed by Salesa et al. [41], the compressive strength and elastic modulus of the first and second generation RACs were evaluated. Except for the slump of the second generation RAC, which decreased by $9 \%$ compared to that of the first generation RAC, significant changes were not observed in the compressive strength and elastic modulus. Zhu et al. [40] observed that the residual mortar content of RCA increased to $38 \%, 55 \%$ and $62 \%$ in proportion to the number of recycling. As expected, the slump value, compressive strength and elastic modulus decreased. According to Zhu et al. [36], decreases in the durability performance of RAC, such as resistance against the freeze-thaw action, chloride penetration and carbonation were observed as RCA was repeatedly reused.

Comprehensively, it seems clear that the multiple uses of RCA result in the low quality of RAC [38]. Marie and Quiasrawi [42] noted that the second generation RCA can replace NA up to $20 \%$ to make the acceptable quality of RAC, while Abed et al. [111] concluded that up to $50 \%$ of the second generation RCA can optimally replace NA. However, the studies referenced in this section appear to address changes in the properties of RCA and RAC that occur when RCA is reused without pretreatment. Therefore, further study can be recommended to evaluate the physical properties of concrete after improving the quality by pre-treating RCA such as removing residual mortar. In addition, a detailed investigation into the durability characteristics of repeatedly recycled RAC is required [112]. Current research into repeatedly recycled RAC evaluates the characteristics of concrete manufactured and crushed in a laboratory, and the consideration of carbonation exposed to the natural environment is insufficient. Carbonation is one of the factors to be considered as it reduces the $\mathrm{pH}$ of concrete and contributes to the corrosion of reinforcement $[113,114]$.

The authors of this review paper believe that it is purposeful, although it is not the only possibility in RAC technology, to consider the repeated use of RCA. The main argument seems to be the depletion of NA deposits, as well as the ecological aspect related to the life cycle of concrete. Concrete can become more environmentally friendly when $\mathrm{CO}_{2}$ absorption of not only concrete elements but also the RCA is more accurately recognized. Concrete during its life cycle absorbs $\mathrm{CO}_{2}$ emitted during cement production and other anthropogenic activities. Different values are given in the literature, from 7.6 to $24 \%$. The disagreement in evaluation is due to different factors influencing concrete carbonation (among others, compressive strength, cement amount, age of concrete structure). This amount can be increased if concrete is treated as a source of material with a greater $\mathrm{CO}_{2}$ absorption capacity as a result of the larger specific surface area of the aggregate [115]. Repeated use of RCA would provide an even greater opportunity for this. Undoubtedly, it leads to a polemic as to what is more important, whether these include technological or 
ecological aspects. Therefore, it is even more legitimate to carry out research and analysis on both of them.

\subsection{Standards of Recycled Aggregate for Concrete}

The first approaches to the standardization of established technological procedures concerning RCA appeared in the late 1970s and early 1980s, first in Japan in 1977 and then in the USA (ASTM C 32-82 and C 125-79) [116] and in some European countries (Germany-DIN 4226-100, Denmark, Great Britain-BS 8500-2) and Brazil (following [11]).

The lack of specific legislation regulating the requirements for the properties of RCA and concretes in some countries is due to the currently still insufficient natural reserves in these countries and the general perception that concrete with RCA has significantly worse properties. In Poland, for example, issues concerning RCA and RAC are only reflected in standards PN-EN 12620:2013 [117] and PN-EN-206:2014 [118]. The Polish Committee for Standardization has adopted draft standards (FprEN 12620:2017, FprEN 13139:2017 and FprEN 13242:2017 [119-121]), which include requirements for RCA, but so far they have not been incorporated by the European Parliament in the harmonized standards package.

The standards of RCA for concrete established in selected countries and several requirements are shown in Table 2.

Table 2. Physical characteristics of RCA specified in some standards.

\begin{tabular}{|c|c|c|c|c|c|}
\hline Standard & Classification & $\begin{array}{c}\text { Minimal Density, } \\
\mathrm{kg} / \mathrm{m}^{3}\end{array}$ & $\begin{array}{l}\text { Maximal Water } \\
\text { Absorption, } \%\end{array}$ & $\begin{array}{c}\text { Maximal Chloride, } \\
\text { Content, \% }\end{array}$ & $\begin{array}{l}\text { Maximal Sulphate } \\
\text { Content, \% }\end{array}$ \\
\hline JIS A5021 [124] (Japan) & High & 2500 & 3 & 0.04 & - \\
\hline JIS A5022 [123] (Japan) & Medium & 2300 & 5 & 0.04 & - \\
\hline JIS A5023 [122] (Japan) & Low & - & 7 & 0.04 & - \\
\hline \multirow{3}{*}{ GB/T 25177 [125] (China) } & Class 1 & 2450 & 3 & 0.06 & 2 \\
\hline & Class 2 & 2350 & 5 & 0.06 & 2 \\
\hline & Class 3 & 2250 & 8 & 0.06 & 2 \\
\hline WBTC-No.12 [126] (Hong Kong) & - & 2000 & 10 & 0.05 & - \\
\hline KS F2527 [127] (Korea) & - & 2500 & 3 & - & - \\
\hline \multirow{3}{*}{ RILEM [128] } & Type I & 1500 & 20 & - & 1 \\
\hline & Type II & 2000 & 10 & - & 1 \\
\hline & Type III & 2400 & 3 & - & 1 \\
\hline HB-155 [131] (Australia) & - & 2100 & 6 & 0.05 & 0.5 \\
\hline NBR-15116 [129] (Brazil) & - & - & 7 & 1 & 1 \\
\hline LNEC-E471 [130] (Portugal) & - & 2200 & 7 & - & 0.8 \\
\hline EHE-08 [132] (Spain) & - & - & 7 & - & 1 \\
\hline
\end{tabular}

Japanese standards classify RCAs for concrete into three levels: low quality [122], medium quality [123] and high quality [124] based on the purpose of use. The low-quality RCA is produced by crushing concrete waste and is used for members where do not require high strength and high durability, and the medium-quality RCA can mainly be used where they are not affected by drying shrinkage and freezing and thawing action except for specific cases. The high-quality RCA is obtained by advanced treatments, and there seems to be no restriction on its use. Chinese standard [125] also divides the quality of RCA into three classes, and the density of RCA is based on the saturated surface-dry condition instead of an oven-dry state. Differently, the Hong Kong [126] and Korean standards [127] do not divide RCA into several groups. The Korean standard [127] requires a minimum oven-dry density of $2500 \mathrm{~kg} / \mathrm{m}^{3}$ and a maximum water absorption of $3 \%$, etc. Compared to the other Asian counties mentioned above, Hong Kong specifications [126] seem to have more relaxed requirements (i.e., a minimum oven-dry density of $2000 \mathrm{~kg} / \mathrm{m}^{3}$ and a maximum water absorption of $10 \%$ ); however, the use of RAC with $100 \%$ RCA replacement is limited to a minor concrete structure, such as concrete benches and planter walls. RILEM [128] classified RCA into three categories: RCA obtained from masonry 
waste (type 1), RCA obtained from concrete waste (type 2), and a combination of RCA and NA (type 3). NBR-15116 [129], LNEC-E471 [130], HB-155 [131] EHE-08 [132] referred to the study by Gonçalves and Brito [133]. Compared to the Asian standards mentioned, the water absorption of these standards is rather high, in the range of $6-7 \%$, but the sulphate content is tightly controlled. Spanish standards EHE-08 [132] recommend the use of a superplasticizer when replacing more than $20 \%$ of RCA due to the high absorption capacity of RCA. The Polish standard PN-EN 12620:2013 [117] classifies aggregates into natural, recycled and artificial and allows their use in concrete technology provided they meet criteria for impurities that may affect the quality of concrete, including water soluble sulphate content and alkaline reactivity for RCAs.

Although the standards may have been established according to the individual circumstances of each country, the density and water absorption ratio required by Japanese, Korean, and Chinese standards are higher than those of other standards. Taking into account the distribution of the absorption rate of RCAs shown in Figure 2, obtaining the high-quality RCA with a water absorption ratio of less than $3 \%$ is considered to need more advanced facilities than the typical RCA production process.

\subsection{Barriers to the Use of Recycled Aggregate Concrete in Practice}

Various studies have been conducted on the feasibility of improving the mechanical properties and durability performance of RAC [134-137]. Hossain et al. [138] conducted a life cycle assessment of RCA and NA production, and concluded that RCA produced from C\&D waste reduced non-renewable energy consumption and greenhouse gas emission by $58 \%$ and $65 \%$, respectively. Similarly, the better environmental benefits of replacing NA with RCA have been reported [139-142], but there are some obstacles to using RCA and RAC in practice.

\subsubsection{Imbalance in Supply and Demand}

According to a case study carried out by Böhmer et al. [143], concrete waste accounts for about $25-40 \%$ of C\&D waste. Assuming that the proportion of the aggregates are $50-60 \%$, due to the losses incurred in the various treatment processes, the actual amount that can be obtained will be less. With the exception of studies to maximize the use of powder and dust generated during the waste concrete process $[46,144,145]$, imbalance in supply and demand of RCA can be a barrier to the recycling of C\&D waste [146,147]. In Korea, the mandatory use ratio of RCA is specified for concrete work in certain construction projects, but if the supply of RCA is difficult due to the distance between the construction site and the RCA supplier, the mandatory use is exempted [148,149].

\subsubsection{Economic Viability}

Economic viability is an important factor influencing C\&D waste management. Manowong [150] mentioned that metal-oriented recycling, which is easily perceived as having economic value, is prioritized in some countries. In the interview study conducted by Wu et al. [151], one interviewee noted that if a regulatory infraction is the most profitable option, it is more likely to be chosen. In fact, due to the limit of monitoring by governments and easy access to illegal reclamation, cases of illegal waste dumping and reclamation are frequently reported [152-154].

Martínez-Lage et al. [155] analyzed the economic feasibility of recycling C\&D waste and stated that distance is one of the major factors affecting cost. A case study in a region in Spain showed that the insufficient number of recycling plants and unfavorable locations would increase transportation distances and, as a result, the use of RAC could increase costs further. Similar analyses were found by [156,157]. Hiete [96] argued that recycling of C\&D waste is most attractive in high-density areas where demand and supply are matched due to the short transport distance, while areas with a low population density are not economically effective. Nunes et al. [158] analyzed two recycling plants with a production capacity of 20 tons and 100 tons per hour, respectively. The authors concluded that C\&D 
waste recycling plants operated by private companies may not be financially suitable under current market conditions in Brazil.

\subsubsection{Negative Perceptions}

Several studies mentioned the negative perception of stakeholders as one of the obstacles to the use of C\&D waste [159-161]. It has been mentioned above that the quality of RCA varies significantly depending on the processing process, and that various equipment and technologies are required to obtain the high-quality RCA. Moreover, the quality may vary depending on the environment exposed during the service life [162].

According to Jong et al. and Taylor-Lange et al. [163,164], concrete with fly ash slightly increased the possibility of indoor radioactive pollution compared to conventional concrete. A large amount of uranium is detected in the waste concrete generated by the demolition of nuclear facilities [165]. In 2011, in Seoul, Korea, radioactivity was detected on asphalt roads mixed with $C \& D$ waste, resulting in a negative perception of the Korean public about C\&D waste materials. These are, for now, individual suggestions in the literature, which in the opinion of the authors of this paper, should be analyzed and emphasized more distinctly.

\section{Conclusions}

The analysis of the literature cited in this paper has allowed the authors to select scientific content, some of which is worthy of research development, particularly in the ecological aspect. The most important threads are presented below.

It is obvious that concrete with RCA is a technologically demanding material of worse quality. The amount of the residual mortar in RCA is considered to be one of the factors that directly reduce properties of RAC. Due to the presence of the residual mortar, RCA has higher water absorption and a lower density in comparison to natural aggregate. However, the rational approach to using RCA for producing next generation concrete, first of all by considering an optimal RCA replacement ratio and the selection of parent concrete types of higher compressive strength seems to be an opportunity to mitigate quality loss of concrete. These two factors are crucial in influencing the quality of next generation concrete with RCA.

Moreover, it is advisable to look for advanced technologies, giving a chance to produce RCA of higher quality with a significant amount of residual mortar removed, and, as a result, RAC of comparable or even higher quality in comparison to concrete types with natural aggregate. This is particularly justified in the case of repeated use of RCA when the residual mortar content attached to a single RCA increases with the increasing number of RCA reuse cycles. It is the opinion of the authors of this review paper that the repeated use of RCA is prosperous from the ecological viewpoint, reducing the depletion of natural aggregate deposits and enhancing the life cycle of concrete. Clearly, more research data including carbonation degree evaluation of RAC are needed to identify a clear trend.

Undoubtedly, harmonization and unification of standards for RCA in individual countries would optimize the rational management not only on an individual scale, but also globally. The latter seems particularly important in the context of a widely perceived and environmentally aware protection. It seems to be crucial because barriers such as economic viability and negative perception of stakeholders in many countries act as factors hindering the practical use of RCA and RAC.

Author Contributions: Conceptualization, J.K. and P.B.; methodology, J.K. and P.B.; formal analysis, J.K. and A.M.G.; data curation, J.K. and A.M.G.; writing-original draft preparation, J.K.; writingreview and editing, A.M.G.; visualization, J.K. and P.B.; supervision, A.M.G. and A.U.; project administration, A.M.G. and A.U. All authors have read and agreed to the published version of the manuscript.

Funding: This research received no external funding.

Institutional Review Board Statement: Not applicable.

Informed Consent Statement: Not applicable. 


\section{Data Availability Statement: Not applicable.}

Conflicts of Interest: The authors declare no conflict of interest.

\section{References}

1. USGS. Mineral Commodity Summaries 2021; USGS: Reston, VA, USA, 2021.

2. UEPG. A Sustainable Industry for a Sustainable Europe; Annual Report; UEPG: Brussels, Belgium, 2020.

3. PMR. Global Construction Aggregates Market; PMR: New York, NY, USA, 2020.

4. Eurostat. Available online: https: / / ec.europa.eu/eurostat $/ \mathrm{tgm} /$ refreshTableAction.do? tab=table\&plugin=1\&pcode=ten00106 \&language=en (accessed on 2 March 2021).

5. EPA. Construction and Demolition Debris: Material-Specific Data. Available online: https://www.epa.gov/facts-and-figuresabout-materials-waste-and-recycling/construction-and-demolition-debris-material (accessed on 7 July 2021).

6. Shi, J.; Xu, Y. Estimation and forecasting of concrete debris amount in China. Resour. Conserv. Recycl. 2006, 49. [CrossRef]

7. Sobotka, A.; Sagan, J.; Sikora, A. Logistyka odzysku w remontach obiektów budowlanych. Mater. Bud. 2016, 134-136. [CrossRef]

8. Eurostat. Generation of Waste by Waste Category, Hazardousness and NACE Rev. 2 Activity. Available online: https:/ / ec.europa. eu/eurostat/databrowser/view/env_wasgen/default/table?lang=en (accessed on 14 November 2021).

9. Jin, J.; Wang, Z.; Ran, S. Solid waste management in Macao: Practices and challenges. Waste Manag. 2006, $26,1045-1051$. [CrossRef] [PubMed]

10. Kim, J. Construction and demolition waste management in Korea: Recycled aggregate and its application. Clean Technol. Environ. Policy 2021, 23, 2223-2234. [CrossRef]

11. Aragão, H.G. Análise Estrutural de Lajes Pré-Moldadas Produzidas com Concreto Reciclado de Construção e Demolição; Universidade Federal de Alagoas: Maceió, Brazil, 2007.

12. Assessment, M.E. Ecosystems and Human Well-Being; Island Press: Washington, DC, USA, 2005; Volume 5.

13. Grabiec, A.M.; Zawal, D.; Rasaq, W.A. The effect of curing conditions on selected properties of recycled aggregate concrete. Appl. Sci. 2020, 10, 4441. [CrossRef]

14. Rahal, K. Mechanical properties of concrete with recycled coarse aggregate. Build. Environ. 2007, 42, 407-415. [CrossRef]

15. Tavakoli, M.; Soroushian, P. Strengths of recycled aggregate concrete made using field-demolished concrete as aggregate. Mater. J. 1996, 93, 178-181.

16. Ajdukiewicz, A.B.; Kliszczewicz, A.T. Comparative tests of beams and columns made of recycled aggregate concrete and natural aggregate concrete. J. Adv. Concr. Technol. 2007, 5, 259-273. [CrossRef]

17. Storey, J.B. Construction Materials Stewardship: The Status Quo in Selected Countries: CIB W115; Centre for Building Performance Research, Victoria University of Wellington: Wellington, New Zealand, 2008; ISBN 906363059X.

18. Eurostat. Record Recycling Rates and Use of Recycled Materials in the EU. Available online: https:/ / ec.europa.eu/eurostat/ documents /2995521/9629294/8-04032019-BP-EN.pdf/295c2302-4ed1-45b9-af86-96d1bbb7acb1 (accessed on 7 July 2021).

19. Tam, V.W.Y.; Soomro, M.; Evangelista, A.C.J. A review of recycled aggregate in concrete applications (2000-2017). Constr. Build. Mater. 2018, 172, 272-292. [CrossRef]

20. Malešev, M.; Radonjanin, V.; Marinković, S. Recycled concrete as aggregate for structural concrete production. Sustainability 2010, 2, 1204-1225. [CrossRef]

21. Fathifazl, G.; Razaqpur, A.G.; Burkan Isgor, O.; Abbas, A.; Fournier, B.; Foo, S. Shear capacity evaluation of steel reinforced recycled concrete (RRC) beams. Eng. Struct. 2011, 33, 1025-1033. [CrossRef]

22. Barreto Santos, M.; de Brito, J.; Santos Silva, A. A review on alkali-silica reaction evolution in recycled aggregate concrete. Materials 2020, 13, 2625. [CrossRef]

23. Bravo, M.; Duarte, A.P.C.; de Brito, J.; Evangelista, L. Tests and simulation of the bond-slip between steel and concrete with recycled aggregates from CDW. Buildings 2021, 11, 40. [CrossRef]

24. Bravo, M.; de Brito, J.; Pontes, J.; Evangelista, L. Shrinkage and creep performance of concrete with recycled aggregates from CDW plants. Mag. Concr. Res. 2017, 69, 974-995. [CrossRef]

25. Bravo, M.; de Brito, J.; Pontes, J.; Evangelista, L. Durability performance of concrete with recycled aggregates from construction and demolition waste plants. Constr. Build. Mater. 2015, 77, 357-369. [CrossRef]

26. Junak, J.; Sicakova, A. Effect of surface modifications of recycled concrete aggregate on concrete properties. Buildings 2017, 8, 2. [CrossRef]

27. Silva, R.V.; de Brito, J.; Dhir, R.K. Fresh-state performance of recycled aggregate concrete: A review. Constr. Build. Mater. 2018, 178, 19-31. [CrossRef]

28. Mi, R.; Pan, G.; Liew, K.M.; Kuang, T. Utilizing recycled aggregate concrete in sustainable construction for a required compressive strength ratio. J. Clean. Prod. 2020, 276, 124249. [CrossRef]

29. Silva, R.V.; de Brito, J.; Dhir, R.K. Use of recycled aggregates arising from construction and demolition waste in new construction applications. J. Clean. Prod. 2019, 236. [CrossRef]

30. Silva, R.V.; de Brito, J.; Dhir, R.K. Tensile strength behaviour of recycled aggregate concrete. Constr. Build. Mater. 2015, 83, 108-118. [CrossRef]

31. Silva, R.V.; de Brito, J.; Dhir, R.K. Comparative analysis of existing prediction models on the creep behaviour of recycled aggregate concrete. Eng. Struct. 2015, 100, 31-42. [CrossRef] 
32. Papatzani, S.; Paine, K. Construction, demolition and excavation waste management in EU/Greece and its potential use in concrete. Fresenius Environ. Bull 2017, 26, 5572-5580.

33. Silva, R.V.; de Brito, J.; Dhir, R.K. Availability and processing of recycled aggregates within the construction and demolition supply chain: A review. J. Clean. Prod. 2017, 143, 598-614. [CrossRef]

34. Behera, M.; Bhattacharyya, S.K.; Minocha, A.K.; Deoliya, R.; Maiti, S. Recycled aggregate from C\&D waste \& its use in concreteA breakthrough towards sustainability in construction sector: A review. Constr. Build. Mater. 2014, 68, 501-516. [CrossRef]

35. Silva, R.V.; de Brito, J.; Dhir, R.K. Properties and composition of recycled aggregates from construction and demolition waste suitable for concrete production. Constr. Build. Mater. 2014, 65, 202-217. [CrossRef]

36. Zhu, P.; Hao, Y.; Liu, H.; Wei, D.; Liu, S.; Gu, L. Durability evaluation of three generations of $100 \%$ repeatedly recycled coarse aggregate concrete. Constr. Build. Mater. 2019, 210, 442-450. [CrossRef]

37. Huda, S.B.; Alam, M.S. Mechanical behavior of three generations of $100 \%$ repeated recycled coarse aggregate concrete. Constr. Build. Mater. 2014, 65, 574-582. [CrossRef]

38. Abreu, V.; Evangelista, L.; de Brito, J. The effect of multi-recycling on the mechanical performance of coarse recycled aggregates concrete. Constr. Build. Mater. 2018, 188, 480-489. [CrossRef]

39. Thomas, C.; de Brito, J.; Gil, V.; Sainz-Aja, J.A.; Cimentada, A. Multiple recycled aggregate properties analysed by X-ray microtomography. Constr. Build. Mater. 2018, 166, 171-180. [CrossRef]

40. Zhu, P.; Zhang, X.; Wu, J.; Wang, X. Performance degradation of the repeated recycled aggregate concrete with $70 \%$ replacement of three-generation recycled coarse aggregate. J. Wuhan Univ. Technol. Sci. Ed. 2016, 31, 989-995. [CrossRef]

41. Salesa, Á.; Pérez-Benedicto, J.A.; Colorado-Aranguren, D.; López-Julián, P.L.; Esteban, L.M.; Sanz-Baldúz, L.J.; Sáez-Hostaled, J.L.; Ramis, J.; Olivares, D. Physico-mechanical properties of multi-recycled concrete from precast concrete industry. J. Clean. Prod. 2017, 141, 248-255. [CrossRef]

42. Marie, I.; Quiasrawi, H. Closed-loop recycling of recycled concrete aggregates. J. Clean. Prod. 2012, 37, 243-248. [CrossRef]

43. Mi, R.; Pan, G.; Li, Y.; Kuang, T.; Lu, X. Distinguishing between new and old mortars in recycled aggregate concrete under carbonation using iron oxide red. Constr. Build. Mater. 2019, 222, 601-609. [CrossRef]

44. Duan, Z.H.; Poon, C.S. Properties of recycled aggregate concrete made with recycled aggregates with different amounts of old adhered mortars. Mater. Des. 2014, 58, 19-29. [CrossRef]

45. Thomas, C.; Setién, J.; Polanco, J.A.; Alaejos, P.; Sánchez De Juan, M. Durability of recycled aggregate concrete. Constr. Build. Mater. 2013, 40, 1054-1065. [CrossRef]

46. Shi, M.; Ling, T.C.; Gan, B.; Guo, M.Z. Turning concrete waste powder into carbonated artificial aggregates. Constr. Build. Mater. 2019, 199, 178-184. [CrossRef]

47. Etxeberria, M.; Vázquez, E.; Marí, A.; Barra, M. Influence of amount of recycled coarse aggregates and production process on properties of recycled aggregate concrete. Cem. Concr. Res. 2007, 37, 735-742. [CrossRef]

48. De Juan, M.S.; Gutiérrez, P.A. Study on the influence of attached mortar content on the properties of recycled concrete aggregate. Constr. Build. Mater. 2009, 23, 872-877. [CrossRef]

49. Suryawanshi, S.R.; Singh, B.; Bhargava, P. Characterization of recycled aggregate concrete. In Advances in Structural Engineering; Springer: Berlin/Heidelberg, Germany, 2015; pp. 1813-1822.

50. Abbas, A.; Fathifazl, G.; Burkan Isgor, O.; Razaqpur, A.G.; Fournier, B.; Foo, S. Proposed method for determining the residual mortar content of recycled concrete aggregates. J. ASTM Int. 2008, 5, 1-12. [CrossRef]

51. Arezoumandi, M.; Smith, A.; Volz, J.S.; Khayat, K.H. An experimental study on flexural strength of reinforced concrete beams with 100\% recycled concrete aggregate. Eng. Struct. 2015, 88, 154-162. [CrossRef]

52. Mi, R.; Liew, K.M.; Pan, G.; Kuang, T. Carbonation resistance study and inhomogeneity evolution of recycled aggregate concretes under loading effects. Cem. Concr. Compos. 2021, 118, 103916. [CrossRef]

53. Sidorova, A.; Vazquez-Ramonich, E.; Barra-Bizinotto, M.; Roa-Rovira, J.J.; Jimenez-Pique, E. Study of the recycled aggregates nature's influence on the aggregate-cement paste interface and ITZ. Constr. Build. Mater. 2014, 68, 677-684. [CrossRef]

54. Afroughsabet, V.; Biolzi, L.; Ozbakkaloglu, T. Influence of double hooked-end steel fibers and slag on mechanical and durability properties of high performance recycled aggregate concrete. Compos. Struct. 2017, 181, 273-284. [CrossRef]

55. Butler, L.J.; West, J.S.; Tighe, S.L. Towards the classification of recycled concrete aggregates: Influence of fundamental aggregate properties on recycled concrete performance. J. Sustain. Cem. Mater. 2014, 3, 140-163. [CrossRef]

56. Nuaklong, P.; Sata, V.; Chindaprasirt, P. Influence of recycled aggregate on fly ash geopolymer concrete properties. J. Clean. Prod. 2016, 112, 2300-2307. [CrossRef]

57. Gokce, A.; Nagataki, S.; Saeki, T.; Hisada, M. Freezing and thawing resistance of air-entrained concrete incorporating recycled coarse aggregate: The role of air content in demolished concrete. Cem. Concr. Res. 2004, 34, 799-806. [CrossRef]

58. Kim, N.; Kim, J.; Yang, S. Mechanical strength properties of RCA concrete made by a modified EMV method. Sustainability 2016, 8, 924. [CrossRef]

59. Yang, S.; Lee, H. Mechanical properties of recycled aggregate concrete proportioned with modified equivalent mortar volume method for paving applications. Constr. Build. Mater. 2017, 136, 9-17. [CrossRef]

60. Fan, Y.; Xiao, J.; Tam, V.W.Y. Effect of old attached mortar on the creep of recycled aggregate concrete. Struct. Concr. 2014, 15, 169-178. [CrossRef] 
61. Padmini, A.K.; Ramamurthy, K.; Mathews, M.S. Influence of parent concrete on the properties of recycled aggregate concrete. Constr. Build. Mater. 2009, 23, 829-836. [CrossRef]

62. Dimitriou, G.; Savva, P.; Petrou, M.F. Enhancing mechanical and durability properties of recycled aggregate concrete. Constr. Build. Mater. 2018, 158, 228-235. [CrossRef]

63. Rajhans, P.; Chand, G.; Kisku, N.; Panda, S.K.; Nayak, S. Proposed mix design method for producing sustainable self compacting heat cured recycled aggregate concrete and its microstructural investigation. Constr. Build. Mater. 2019, 218, 568-581. [CrossRef]

64. Pandurangan, K.; Dayanithy, A.; Om Prakash, S. Influence of treatment methods on the bond strength of recycled aggregate concrete. Constr. Build. Mater. 2016, 120, 212-221. [CrossRef]

65. Domingo-Cabo, A.; Lázaro, C.; López-Gayarre, F.; Serrano-López, M.A.; Serna, P.; Castaño-Tabares, J.O. Creep and shrinkage of recycled aggregate concrete. Constr. Build. Mater. 2009, 23, 2545-2553. [CrossRef]

66. Sasanipour, H.; Aslani, F. Durability properties evaluation of self-compacting concrete prepared with waste fine and coarse recycled concrete aggregates. Constr. Build. Mater. 2020, 236, 117540. [CrossRef]

67. Fan, Y.; Niu, H.; Zhang, X. Impact of the properties of old mortar on creep prediction model of recycled aggregate concrete. Constr. Build. Mater. 2020, 239, 117772. [CrossRef]

68. Abbas, A.; Fathifazl, G.; Isgor, O.B.; Razaqpur, A.G.; Fournier, B.; Foo, S. Durability of recycled aggregate concrete designed with equivalent mortar volume method. Cem. Concr. Compos. 2009, 31, 555-563. [CrossRef]

69. Anike, E.E.; Saidani, M.; Ganjian, E.; Tyrer, M.; Olubanwo, A.O. Evaluation of conventional and equivalent mortar volume mix design methods for recycled aggregate concrete. Mater. Struct. 2020, 53, 1-15. [CrossRef]

70. McGinnis, M.J.; Davis, M.; de la Rosa, A.; Weldon, B.D.; Kurama, Y.C. Strength and stiffness of concrete with recycled concrete aggregates. Constr. Build. Mater. 2017, 154, 258-269. [CrossRef]

71. Gholampour, A.; Ozbakkaloglu, T. Time-dependent and long-term mechanical properties of concretes incorporating different grades of coarse recycled concrete aggregates. Eng. Struct. 2018, 157, 224-234. [CrossRef]

72. Kim, Y.; Hanif, A.; Usman, M.; Park, W. Influence of bonded mortar of recycled concrete aggregates on interfacial characteristicsPorosity assessment based on pore segmentation from backscattered electron image analysis. Constr. Build. Mater. 2019, 212, 149-163. [CrossRef]

73. KATS. KS L5201 Portland Cement; Korean Agency Technology Standards: Eumseong-gun, Korea, 2016.

74. ASTM. ASTM C150/C150M-20 Standard Specification for Portland Cement; ASTM: West Conshohocken, PA, USA, 2020.

75. Limbachiya, M.C.; Marrocchino, E.; Koulouris, A. Chemical-mineralogical characterisation of coarse recycled concrete aggregate. Waste Manag. 2007, 27, 201-208. [CrossRef]

76. Bui, N.K.; Satomi, T.; Takahashi, H. Recycling woven plastic sack waste and PET bottle waste as fiber in recycled aggregate concrete: An experimental study. Waste Manag. 2018, 78, 79-93. [CrossRef]

77. Kim, J.; Kim, N.; Yang, S. The effect of the residual mortar of recycled concrete aggregate on alkali silica reaction. Int. J. Highw. Eng. 2015, 17, 19-24. [CrossRef]

78. Medina, C.; Zhu, W.; Howind, T.; Frías, M.; de Sánchez Rojas, M.I. Effect of the constituents (asphalt, clay materials, floating particles and fines) of construction and demolition waste on the properties of recycled concretes. Constr. Build. Mater. 2015, 79, 22-33. [CrossRef]

79. Sánchez-Cotte, E.H.; Pacheco-Bustos, C.A.; Fonseca, A.; Triana, Y.P.; Mercado, R.; Yepes-Martínez, J.; Lagares Espinoza, R.G. The chemical-mineralogical characterization of recycled concrete aggregates from different sources and their potential reactions in asphalt mixtures. Materials 2020, 13, 5592. [CrossRef] [PubMed]

80. Saravanakumar, P.; Abhiram, K.; Manoj, B. Properties of treated recycled aggregates and its influence on concrete strength characteristics. Constr. Build. Mater. 2016, 111, 611-617. [CrossRef]

81. Martínez, I.; Etxeberria, M.; Pavón, E.; Díaz, N. Influence of demolition waste fine particles on the properties of recycled aggregate masonry mortar. Int. J. Civ. Eng. 2018, 16, 1213-1226. [CrossRef]

82. Moreno-Pérez, E.; Hernández-Ávila, J.; Rangel-Martínez, Y.; Cerecedo-Sáenz, E.; Arenas-Flores, A.; Reyes-Valderrama, M.; Salinas-Rodríguez, E. Chemical and mineralogical characterization of recycled aggregates from construction and demolition waste from Mexico City. Minerals 2018, 8, 237. [CrossRef]

83. Krour, H.; Trauchessec, R.; Lecomte, A.; Diliberto, C.; Barnes-Davin, L.; Bolze, B.; Delhay, A. Incorporation rate of recycled aggregates in cement raw meals. Constr. Build. Mater. 2020, 248, 118217. [CrossRef]

84. Park, S.S.; Kim, S.J.; Chen, K.Q.; Lee, Y.J.; Lee, S.B. Crushing characteristics of a recycled aggregate from waste concrete. Constr. Build. Mater. 2018, 160, 100-105. [CrossRef]

85. Rajan, B.; Singh, D. Investigation on effects of different crushing stages on morphology of coarse and fine aggregates. Int. J. Pavement Eng. 2020, 21, 177-195. [CrossRef]

86. Matias, D.; de Brito, J.; Rosa, A.; Pedro, D. Mechanical properties of concrete produced with recycled coarse aggregates-Influence of the use of superplasticizers. Constr. Build. Mater. 2013, 44, 101-109. [CrossRef]

87. Öztürk, A.U.; Erdem, R.T.; Kozanoglu, C. Investigation of crushing type of concrete aggregates on mechanical properties of concrete. Int. J. Mater. Eng. 2012, 2, 6-9. [CrossRef]

88. Cepuritis, R.; Garboczi, E.J.; Jacobsen, S. Three dimensional shape analysis of concrete aggregate fines produced by VSI crushing Powder Technol. 2017, 308, 410-421. [CrossRef] 
89. Ulsen, C.; Tseng, E.; Angulo, S.C.; Landmann, M.; Contessotto, R.; Balbo, J.T.; Kahn, H. Concrete aggregates properties crushed by jaw and impact secondary crushing. J. Mater. Res. Technol. 2019, 8, 494-502. [CrossRef]

90. Kamani, M.; Ajalloeian, R. The effect of rock crusher and rock type on the aggregate shape. Constr. Build. Mater. 2020, $230,117016$. [CrossRef]

91. Liu, Y.; Sun, W.; Nair, H.; Lane, D.S.; Wang, L. Quantification of aggregate morphologic characteristics with the correlation to uncompacted void content of coarse aggregates in Virginia. Constr. Build. Mater. 2016, 124, 645-655. [CrossRef]

92. Nagataki, S.; Gokce, A.; Saeki, T.; Hisada, M. Assessment of recycling process induced damage sensitivity of recycled concrete aggregates. Cem. Concr. Res. 2004, 34, 965-971. [CrossRef]

93. Pedro, D.; de Brito, J.; Evangelista, L. Performance of concrete made with aggregates recycled from precasting industry waste: Influence of the crushing process. Mater. Struct. 2015, 48, 3965-3978. [CrossRef]

94. KORAS. Casebook of Recycled Aggregate and Recycled Aggregate Product; KORAS: Seoul, Korea, 2020. Available online: https:/ / www.me. go.kr/home/ file/ readDownloadFile.do?fileId=158651\&fileSeq=1 (accessed on 2 March 2021).

95. Tam, V.W.Y.; Tam, C.M. Crushed aggregate production from centralized combined and individual waste sources in Hong Kong. Constr. Build. Mater. 2007, 21, 879-886. [CrossRef]

96. Hiete, M. Waste management plants and technology for recycling construction and demolition (C\&D) waste: State-of-the-art and future challenges. In Handbook of Recycled Concrete and Demolition Waste; Elsevier Inc.: Amsterdam, The Netherlands, 2013; pp. 53-75, ISBN 9780857096906.

97. Tam, V.W.Y.; Tam, C.M.; Le, K.N. Removal of cement mortar remains from recycled aggregate using pre-soaking approaches. Resour. Conserv. Recycl. 2007, 50, 82-101. [CrossRef]

98. Kim, Y.; Hanif, A.; Kazmi, S.M.S.; Munir, M.J.; Park, C. Properties enhancement of recycled aggregate concrete through pretreatment of coarse aggregates-Comparative assessment of assorted techniques. J. Clean. Prod. 2018, 191, 339-349. [CrossRef]

99. Akbarnezhad, A.; Ong, K.C.G.; Zhang, M.H.; Tam, C.T.; Foo, T.W.J. Microwave-assisted beneficiation of recycled concrete aggregates. Constr. Build. Mater. 2011, 25, 3469-3479. [CrossRef]

100. Linß, E.; Mueller, A. High-performance sonic impulses-An alternative method for processing of concrete. Proc. Int. J. Miner. Process. 2004, 74, S199-S208. [CrossRef]

101. Tam, V.W.Y.; Butera, A.; Le, K.N.; Li, W. Utilising $\mathrm{CO}_{2}$ technologies for recycled aggregate concrete: A critical review. Constr. Build. Mater. 2020, 250, 118903. [CrossRef]

102. Grabiec, A.M.; Klama, J.; Zawal, D.; Krupa, D. Modification of recycled concrete aggregate by calcium carbonate biodeposition. Constr. Build. Mater. 2012, 34, 145-150. [CrossRef]

103. Quattrone, M.; Angulo, S.C.; John, V.M. Energy and $\mathrm{CO}_{2}$ from high performance recycled aggregate production. Resour. Conserv. Recycl. 2014, 90, 21-33. [CrossRef]

104. Ahmad Bhat, J. Effect of strength of parent concrete on the mechanical properties of recycled aggregate concrete. Mater. Today Proc. 2021, 42, 1462-1469. [CrossRef]

105. Tabsh, S.W.; Abdelfatah, A.S. Influence of recycled concrete aggregates on strength properties of concrete. Constr. Build. Mater. 2009, 23, 1163-1167. [CrossRef]

106. Xiao, J.; Li, J.; Zhang, C. Mechanical properties of recycled aggregate concrete under uniaxial loading. Cem. Concr. Res. 2005, 35, 1187-1194. [CrossRef]

107. Vieira, G.L.; Schiavon, J.Z.; Borges, P.M.; da Silva, S.R.; de Oliveira Andrade, J.J. Influence of recycled aggregate replacement and fly ash content in performance of pervious concrete mixtures. J. Clean. Prod. 2020, 271, 122665. [CrossRef]

108. Kou, S.C.; Poon, C.S. Effect of the quality of parent concrete on the properties of high performance recycled aggregate concrete. Constr. Build. Mater. 2015, 77, 501-508. [CrossRef]

109. Wang, Q.; Geng, Y.; Wang, Y.; Zhang, H. Drying shrinkage model for recycled aggregate concrete accounting for the influence of parent concrete. Eng. Struct. 2020, 202, 109888. [CrossRef]

110. Geng, Y.; Wang, Q.; Wang, Y.; Zhang, H. Influence of service time of recycled coarse aggregate on the mechanical properties of recycled aggregate concrete. Mater. Struct. 2019, 52, 97. [CrossRef]

111. Abed, M.; Nemes, R.; Tayeh, B.A. Properties of self-compacting high-strength concrete containing multiple use of recycled aggregate. J. King Saud Univ. Eng. Sci. 2020, 32, 108-114. [CrossRef]

112. Thomas, C.; de Brito, J.; Cimentada, A.; Sainz-Aja, J.A. Macro- and micro- properties of multi-recycled aggregate concrete. J. Clean. Prod. 2020, 245, 118843. [CrossRef]

113. Mi, R.; Pan, G.; Kuang, T. Reducing the carbonation zone and steel corrosion zone widths of recycled aggregate concrete by optimizing its mixing process. J. Mater. Civ. Eng. 2021, 33, 04021061. [CrossRef]

114. Mi, R.; Pan, G.; Li, Y.; Kuang, T. Carbonation degree evaluation of recycled aggregate concrete using carbonation zone widths. J. $\mathrm{CO}_{2}$ Util. 2021, 43, 101366. [CrossRef]

115. Possan, E.; Felix, E.F.; Thomaz, W.A. $\mathrm{CO}_{2}$ uptake by carbonation of concrete during life cycle of building structures. J. Build. Pathol. Rehabil. 2016, 1, 1-9. [CrossRef]

116. Hansen, T.C.; Hedegkd, S.E. Properties of recycled aggregate concretes as affected by admixtures in original concretes. Proc. J. Proc. 1984, 81, 21-26.

117. PKN. PN-EN 12620:2013 Aggregates for Concrete; Polish Committee for Standardization: Warsaw, Poland, 2013. 
118. PKN. PN-EN-206:2014 Concrete—Requirements, Properties and Conformity; Polish Committee for Standardization: Warsaw, Poland, 2014.

119. CENELEC. FprEN 12620:2017 Aggregates for Concrete; CENELEC: Brussels, Belgium, 2017.

120. CENELEC. FprEN 13139:2017 Aggregates for Mortar; CENELEC: Brussels, Belgium, 2017.

121. CENELEC. FprEN 13242:2017 Aggregates for Unbound and Hydraulically Bound Materials for Use in Civil Engineering Work and Road Construction; CENELEC: Brussels, Belgium, 2017.

122. JSA. JIS A 5023 Recycled Aggregate for Concrete-Class L; Japanese Standards Association: Tokyo, Japan, 2018.

123. JSA. JIS A 5022 Recycled Aggregate for Concrete-Class M; Japanese Standards Association: Tokyo, Japan, 2018.

124. JSA. JIS A 5021 Recycled Aggregate for Concrete-Class H; Japanese Standards Association: Tokyo, Japan, 2018.

125. CNS. GB/T 25177-2010 Standard for Recycled Coarse Aggregate for Concrete; China National Standard: Beijing, China, 2010.

126. WBTC. WBTC No.12/2002 Specifications Facilitating the Use of Recycled Aggregates; Works Bureau Technical Circular: Hong Kong, China, 2004.

127. KATS. KS F2527 Aggregates for Concrete; Korean Agency for Technology Standards: Eumseong-gun, Korea, 2020.

128. Rilem, T.C. 121-DRG. Specifications for concrete with recycled aggregates. Mater. Struct. 1994, 27, 557-559.

129. ABNT. NBR 15116 Recycled Aggregates from Construction and Demolition Waste: Non-Structural Concrete-Requirements; Assoiacao Brasileira de Normas Tecnicas: São Paulo, Brazil, 2005.

130. LNEC. LNEC E 471 Guideline for the Use of Recycled Coarse Aggregates in Hydraulic Binders' Concrete; LNEC: Lisboa, Portugal, 2006.

131. CRISO. HB-155, 2002 Guide to the Use of Recycled Concrete and Masonry Materials; Commonwealth Scientific and Industrial Research Organisation: Canberra, Austraila, 2002.

132. Spanish Ministry of Public Works. EHE-08 Instrucción Del Hormigón Estructural EHE-08 (Spanish Structural Concrete Code); Spanish Ministry of Public Works: Madrid, Spain, 2008.

133. Gonçalves, P.; de Brito, J. Recycled aggregate concrete (RAC)-comparative analysis of existing specifications. Mag. Concr. Res. 2010, 62, 339-346. [CrossRef]

134. Pani, L.; Francesconi, L.; Rombi, J.; Mistretta, F.; Sassu, M.; Stochino, F. Effect of parent concrete on the performance of recycled aggregate concrete. Sustainability 2020, 12, 9399. [CrossRef]

135. Katz, A. Treatments for the improvement of recycled aggregate. J. Mater. Civ. Eng. 2004, 16, 597-603. [CrossRef]

136. Kim, J. Properties of recycled aggregate concrete designed with equivalent mortar volume mix design. Constr. Build. Mater. 2021, 301, 124091. [CrossRef]

137. Bravo-German, A.M.; Bravo-Gómez, I.D.; Mesa, J.A.; Maury-Ramírez, A. Mechanical properties of concrete using recycled aggregates obtained from old paving stones. Sustainability 2021, 13, 44. [CrossRef]

138. Hossain, M.U.; Poon, C.S.; Lo, I.M.C.; Cheng, J.C.P. Comparative environmental evaluation of aggregate production from recycled waste materials and virgin sources by LCA. Resour. Conserv. Recycl. 2016, 109, 67-77. [CrossRef]

139. Ding, T.; Xiao, J.; Tam, V.W.Y. A closed-loop life cycle assessment of recycled aggregate concrete utilization in China. Waste Manag. 2016, 56, 367-375. [CrossRef]

140. Zhang, C.; Hu, M.; Dong, L.; Xiang, P.; Zhang, Q.; Wu, J.; Li, B.; Shi, S. Co-benefits of urban concrete recycling on the mitigation of greenhouse gas emissions and land use change: A case in Chongqing metropolis, China. J. Clean. Prod. 2018, 201, 481-498. [CrossRef]

141. Estanqueiro, B.; Dinis Silvestre, J.; de Brito, J.; Duarte Pinheiro, M. Environmental life cycle assessment of coarse natural and recycled aggregates for concrete. Eur. J. Environ. Civ. Eng. 2018, 22, 429-449. [CrossRef]

142. Mesa, J.A.; Fúquene-Retamoso, C.; Maury-Ramírez, A. Life cycle assessment on construction and demolition waste: A systematic literature review. Sustainability 2021, 13, 7676. [CrossRef]

143. Böhmer, S.; Moser, G.; Neubauer, C.; Peltoniemi, M.; Schachermayer, E.; Tesar, M.; Walter, B.; Winter, B. Aggregates Case Study; Contract No 150787-2007 F1SC-AT; ISO: Geneva, Switzerland, 2008.

144. Xiao, J.; Ma, Z.; Sui, T.; Akbarnezhad, A.; Duan, Z. Mechanical properties of concrete mixed with recycled powder produced from construction and demolition waste. J. Clean. Prod. 2018, 188, 720-731. [CrossRef]

145. Ahmari, S.; Ren, X.; Toufigh, V.; Zhang, L. Production of geopolymeric binder from blended waste concrete powder and fly ash. Constr. Build. Mater. 2012, 35, 718-729. [CrossRef]

146. Earle, J.; Ergun, D.; Gorgolewski, M. Barriers for Deconstruction and Reuse/Recycling of Construction Materials in Canada; CIB: Ottawa, ON, Canada, 2014; Volume 20.

147. Tam, V.W.Y. Economic comparison of concrete recycling: A case study approach. Resour. Conserv. Recycl. 2008, 52, 821-828. [CrossRef]

148. MoE. Construction Waste Recycling Promotion Act, No. 16317; Ministry of Environment: Seoul, Korea, 2019.

149. MOLIT. Regulations on the Mandatory Use of Recycled Aggregates for Construction Projects; Ministry of Land, Infrastructure and Transport: Seoul, Korea, 2009.

150. Manowong, E. Investigating factors influencing construction waste management efforts in developing countries: An experience from Thailand. Waste Manag. Res. 2012, 30, 56-71. [CrossRef] [PubMed]

151. Wu, Z.; Yu, A.T.W.; Shen, L. Investigating the determinants of contractor's construction and demolition waste management behavior in Mainland China. Waste Manag. 2017, 60, 290-300. [CrossRef] 
152. Nagapan, S.; Rahman, I.A.; Asmi, A.; Memon, A.H.; Latif, I. Issues on construction waste: The need for sustainable waste management. In Proceedings of the 2012 IEEE Colloquium on Humanities, Science and Engineering (CHUSER), Kota Kinabalu, Malaysia, 3-4 December 2012.

153. Lu, W. Big data analytics to identify illegal construction waste dumping: A Hong Kong study. Resour. Conserv. Recycl. 2019, 141, 264-272. [CrossRef]

154. Dladla, I.; Machete, F.; Shale, K. A review of factors associated with indiscriminate dumping of waste in eleven African countries. Afr. J. Sci. Technol. Innov. Dev. 2016, 8, 475-481. [CrossRef]

155. Martínez-Lage, I.; Vázquez-Burgo, P.; Velay-Lizancos, M. Sustainability evaluation of concretes with mixed recycled aggregate based on holistic approach: Technical, economic and environmental analysis. Waste Manag. 2020, 104, 9-19. [CrossRef]

156. Marinković, S.; Radonjanin, V.; Malešev, M.; Ignjatović, I. Comparative environmental assessment of natural and recycled aggregate concrete. Waste Manag. 2010, 30, 2255-2264. [CrossRef] [PubMed]

157. Faleschini, F.; Zanini, M.A.; Pellegrino, C.; Pasinato, S. Sustainable management and supply of natural and recycled aggregates in a medium-size integrated plant. Waste Manag. 2016, 49, 146-155. [CrossRef]

158. Nunes, K.R.A.; Mahler, C.F.; Valle, R.; Neves, C. Evaluation of investments in recycling centres for construction and demolition wastes in Brazilian municipalities. Waste Manag. 2007, 27, 1531-1540. [CrossRef]

159. Jin, R.; Li, B.; Zhou, T.; Wanatowski, D.; Piroozfar, P. An empirical study of perceptions towards construction and demolition waste recycling and reuse in China. Resour. Conserv. Recycl. 2017, 126, 86-98. [CrossRef]

160. Shooshtarian, S.; Caldera, S.; Maqsood, T.; Ryley, T. Using Recycled Construction and demolition waste products: A review of stakeholders' perceptions, decisions, and motivations. Recycling 2020, 5, 31. [CrossRef]

161. Rao, A.; Jha, K.N.; Misra, S. Use of aggregates from recycled construction and demolition waste in concrete. Resour. Conserv. Recycl. 2007, 50, 71-81. [CrossRef]

162. Min, B.; Park, J.-W.; Choi, W.-K.; Lee, K.-W. Separation of radionuclide from dismantled concrete waste. J. Nucl. Fuel Cycle Waste Technol. 2009, 7, 79-86.

163. Taylor-Lange, S.C.; Stewart, J.G.; Juenger, M.C.G.; Siegel, J.A. The contribution of fly ash toward indoor radon pollution from concrete. Build. Environ. 2012, 56, 276-282. [CrossRef]

164. De Jong, P.; Van Dijk, W.; Van Hulst, J.G.A.; Van Heijningen, R.J.J. The effect of the composition and production process of concrete on the 222Rn Exhalation rate. In Proceedings of the 1995 6th International Symposium on the Natural Radiation Environment, Montreal, QC, Canada, 5-9 June 1995; Elsevier Science Ltd.: Amsterdam, The Netherlands, 1997; Volume 22, pp. $287-293$.

165. Lee, Y.J.; Hwang, D.S.; Lee, K.W.; Jeong, G.H.; Moon, J.K. Characterization of cement waste form for final disposal of decommissioned concrete waste. J. Nucl. Fuel Cycle Waste Technol. 2013, 11, 271-280. [CrossRef] 